Website publication $10 \mathrm{~J}$ une 1998

ThE role of NMDA and non-NMDA receptors of the area postrema (AP) in the control of respiration and gastric motility was investigated in anaesthetized rabbits using microinjections $(10-20 \mathrm{nl})$ of specific agonists or antagonists. N MDA $(20 \mathrm{mM})$ or A MPA $(10 \mathrm{mM})$ caused excitatory effects on respiration and gastric relaxation. Selective blockade of N MDA or non-N MDA receptors, respectively with $\mathrm{D}(-)$-2-amino-5-phosphonopentanoic acid (D-AP5; $10 \mathrm{mM}$ ) and 6-nitro-7-sulphamoylbenzo(f)quinoxaline-2,3-dione (N BQ X; 5 mM ), decreased respiratory frequency and increased gastric tone. Both these effects were more marked following non-N MDA receptor blockade and were prevented by vagotomy. These findings show that NMDA and non-NMDA receptors are present on AP neurones and have a role in the tonic control of respiration and gastric motility. N euroR eport 9: 2057-2062 @ 1998 R apid Science Ltd.

Key words: A rea postrema; Brain stem; Excitatory amino acid receptors; $\mathrm{G}$ astric motility; Rabbit; R espiration; Vagus nerve
N euroReport 9, 2057-2062 (1998)

\section{Area postrema glutamate receptors mediate respiratory and gastric responses in the rabbit}

\section{Fulvia Bongianni, Donatella Mutolo, Marco Carfi and Tito Pantaleo ${ }^{\mathrm{CA}}$}

Dipartimento di Scienze Fisiologiche, Università degli Studi di Firenze, Viale G. B. Morgagni 63, I-50134 Firenze, Italy

${ }^{\mathrm{CA} C}$ orresponding A uthor

\section{Introduction}

The area postrema (AP) receives significant visceral (vagal, glossopharyngeal) afferent projections and has extensive connections with other regions of the central nervous system ${ }^{1-3}$ involved in the control of respiration and gastric motility. The primary function attributed to the AP has been that of a chemoceptive trigger zone for emesis. ${ }^{4} \mathrm{H}$ ow ever, this region has been implicated in various other physiological functions, such as arousal, control of caloric and fluid homeostasis and cardiovascular regulation. ${ }^{4}$ R ecently, we have provided evidence that the AP is involved in the control of both respiration and gastric motility; microinjections of DL-homocysteic acid (DLH), the broad-spectrum excitatory amino acid (EAA) agonist, provoked marked excitatory effects on respiration associated with gastric relaxation. ${ }^{5,6}$ EA As are believed to mediate much of the fast excitatory synaptic transmission within the central nervous system by acting on ionotropic receptors, i.e. N M D A and non-N MDA or AMPA/kainate receptors. ${ }^{7}$

The purpose of this study was twofold. The first purpose was to extend our previous finding by determining whether both N M DA and non-N MDA receptors are involved in mediating $\mathrm{DLH}$-induced respiratory and gastric responses. The second purpose was to ascertain whether ionotropic EAA receptors have a role in mediating tonic influences of A P neurones on both respiratory activity and gastric motility by making use of selective antagonists.

\section{Materials and Methods}

Experiments were carried out on 18 male $\mathrm{N} \mathrm{ew}$ Zealand white rabbits $(2.7-3.2 \mathrm{~kg})$ anaesthetized with a mixture of $\alpha$-chloralose $\left(40 \mathrm{mg} \mathrm{kg}^{-1}\right.$, i.v.; Sigma Chemical, St. Louis, M O , U SA) and urethane (800 mg kg-1, i.v.), supplemented when necessary ( $4 \mathrm{mg} \mathrm{kg}^{-1}$ and $80 \mathrm{mg} \mathrm{kg}^{-1}$, respectively). The state of the pupil (constriction) and the absence of reflex withdrawal of the hindlimbs to nociceptive stimuli ensured full surgical anaesthesia. A II animal care and experimental procedures were conducted in accordance with the Italian legislation and the official regulations of the European Communities Council on use of laboratory animals.

Following cannulation of the trachea, polyethylene catheters were inserted into a femoral artery and vein for recording of arterial blood pressure and systemic administration of drugs, respectively. Both $\mathrm{C}_{5}$ phrenic roots were dissected free, cut distally and prepared for recordings. Both cervical vagus nerves were separated from the sympathetic trunks for subsequent vagotomy. The animal was placed in a prone position and fixed by a stereotaxic head holder and vertebral clamps. The medulla was widely exposed by occipital craniotomy. Body temperature was maintained at $38 \pm 0.5^{\circ} \mathrm{C}$ by a heating blanket controlled through a rectal thermistor probe. The animals were generally spontaneously breathing; however, during the course of the experiment some of them $(n=10)$ were bilaterally vagotomized, 
paralysed (gallamine triethiodide $4 \mathrm{mg} \mathrm{kg}{ }^{-1}$, i.v., supplemented with $2 \mathrm{mg} \mathrm{kg}^{-1}$ every $30 \mathrm{~min}$, Sigma) and artificially ventilated. In paralysed preparations, the adequacy of anaesthesia was assessed by the absence of fluctuations in arterial blood pressure or phrenic nerve activity, whether spontaneous or in response to somatic nociceptive stimuli.

Efferent phrenic nerve activity was recorded from desheathed $C_{5}$ phrenic roots using bipolar platinum electrodes, amplified, full-wave rectified and integrated (low-pass filter, time constant $100 \mathrm{~ms}$ ). Mean arterial blood pressure (MAP) was recorded by a strain gauge manometer. End-tidal $\mathrm{CO}_{2}$ was monitored by means of an infrared $\mathrm{CO}_{2}$ analyser (Datex CD-102, N ormocap, Helsinki, Finland). In artificially ventilated animals, end-tidal $\mathrm{CO}_{2}$ was kept at desired levels (4-5\%) by adjusting the frequency and stroke volume of the respiratory pump. Gastric motility was recorded by means of a large flaccid (rubber) balloon passed down the oesophagus into the stomach, according to a technique described previously. ${ }^{8}$ The balloon was filled with warm water $\left(38^{\circ} \mathrm{C}\right)$ and connected to a wide diameter reservoir. Gastric motility was recorded isotonically ${ }^{9}$ with a strain gauge manometer connected to the reservoir. Basal gastric volume was set at $-65 \mathrm{ml}$ by elevating the reservoir and causing an influx of fluid into the balloon (load $5-7 \mathrm{~cm}$ of water). The signals of all variables studied were continuously monitored on an 8-channel rectilinearly writing chart recorder (Model 8K20, NEC San-ej Instruments, Tokyo, Japan). Microinjections (10-20 nl) of different EAA receptor agonists and antagonists were made into the AP at appropriate depths $(150-300 \mu \mathrm{m})$. The following drugs (Tocris Cookson, Bristol, UK) were used: NMDA $(20 \mathrm{mM})$, AMPA $(10 \mathrm{mM})$, the NMDA receptor antagonist $D(-)-2$-amino-5-phosphonopentanoic acid (D-AP5; $10 \mathrm{mM}$ ) and the non-NMDA receptor antagonist 6-nitro-7-sulphamoylbenzo(f)quinoxal ine-2,3-dione (N BQX; $5 \mathrm{mM}$ ).

Agonist concentrations were selected in preliminary trials in order to consistently obtain effects on respiratory and gastric motility similar to those previously reported with $160 \mathrm{mM}$ DLH microinjections into the AP. ${ }^{5}$ A ntagonist concentrations were in the same range of those reported to be effective and selective in blocking EAA transmission in the medulla of in vivo preparations. ${ }^{10}$ In addition, the effectiveness of EAA receptor blockade was determined empirically: 20 mM N MDA or 10 mM AMPA was completely ineffective when injected into the AP 3-5 min following a microinjection at the same site as $10 \mathrm{mM}$ D-AP5 $(\mathrm{n}=2)$ or $5 \mathrm{mM} \mathrm{NBQX}$ $(n=3)$, respectively. The drugs were dissolved in $0.9 \% \mathrm{~N} \mathrm{aCl}$ solution containing in most experiments $0.1-0.2 \%$ Pontamine sky blue to mark the injection site; the $\mathrm{pH}$ was adjusted to 7.4 with $0.1 \mathrm{~N} \mathrm{NaOH}$. The injections were performed via a glass micropipette (tip diameter 10-25 $\mu \mathrm{m}$ ) by applying pressure using an air-filled syringe connected to the micropipette by polyethylene tubing. The volume of the injectate was measured directly by monitoring the movement of the fluid meniscus in the pipette barre with a dissecting microscope equipped with a fine reticule The time taken to inject the solution ranged from 5 to $10 \mathrm{~s}$. Control injections of equal volumes of vehicle solutions were also performed.

At the end of the experiment the brain was removed and fixed in $10 \%$ formol saline Frozen coronal sections $(20 \mu \mathrm{m})$ stained with cresyl violet were used for the histological control of pipettetracks and injection sites. The atlas of Shek et al. ${ }^{11}$ was used for comparison.

The respiratory frequency (breaths $\mathrm{min}^{-1}$ ), inspiratory time, expiratory time and peak amplitude of the integrated phrenic nerve activity (arbitrary units) were measured on paper recordings (usual paper speed $2 \mathrm{~mm} \mathrm{~s}^{-1} ; 10 \mathrm{~mm} \mathrm{~s}^{-1}$ for expanded traces). When a level of tonic phrenic activity developed in response to chemical stimulation (see Results), it was included in the measurement of peak phrenic amplitude Respiratory variables were measured for an average of five consecutive breaths both in the period imme diately preceding each trial and at the time when the maximum response to injected drugs occurred (see Results). Gastric volume and MAP were measured at $2 \mathrm{~s}$ intervals for $20 \mathrm{~s}$ and averaged both during control periods and during maximum responses to drug application. O wing to the small variations in the studied variables within a measurement period, the average value for each period was taken as a single measurement for purpose of analysis. Statistical analysis of data was performed using Wilcoxon signed rank tests or Mann-Whitney tests. All values are presented as means \pm s.e.; $p<0.05$ was considered as significant.

\section{Results}

The respiratory responses to microinjections (10$20 \mathrm{nl})$ of $20 \mathrm{mM}$ NMDA $(0.2-0.4 \mathrm{nmol})$ and $10 \mathrm{mM}$ AMPA (0.1-0.2 nmol) into the AP (mid-line or just lateral to the mid-line, $>0.6 \mathrm{~mm}$ caudal to the rostral margin of the AP at $150-300 \mu \mathrm{m}$ depth) mainly consisted of a progressive and marked increase in respiratory frequency, usually associated with the development of tonic phrenic activity without any significant change in peak phrenic amplitude (Fig. 1). In both cases the onset of the responses was rela tively rapid (10-30 s from the start of the injection); the maximum response occurred within 50-120 s, while a complete recovery was usually observed after 


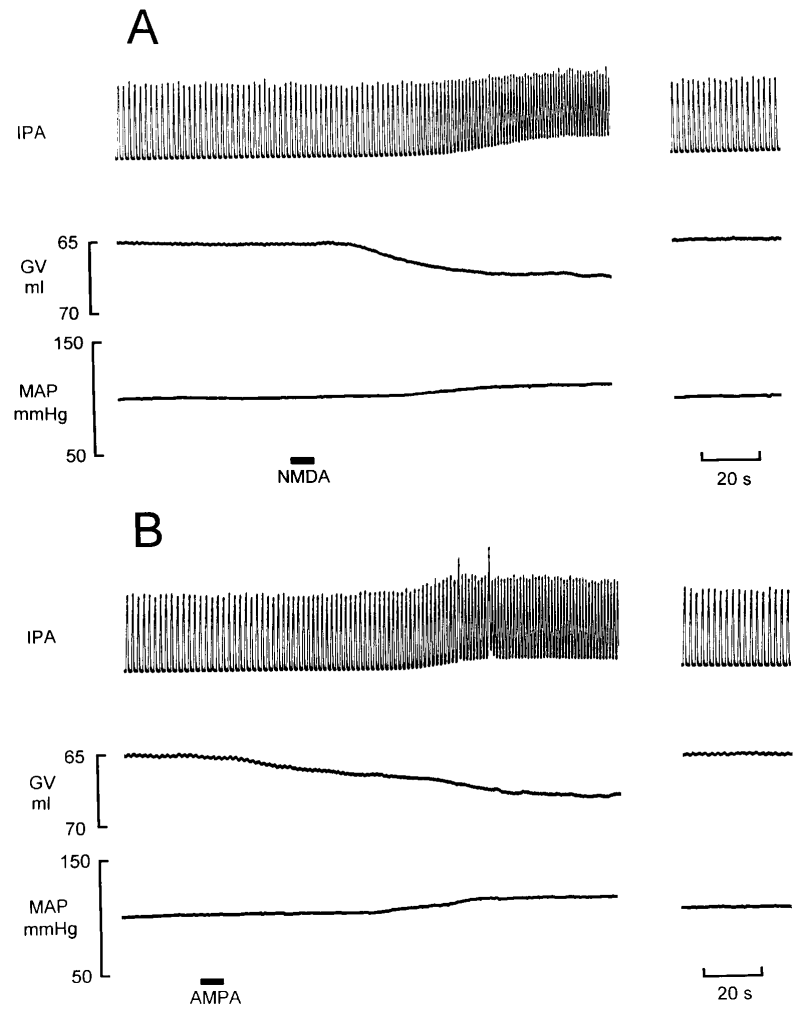

FIG. 1. Effects on integrated phrenic nerve activity (IPA), gastric volume (GV) and mean arterial blood pressure (MAP) in response to microinjections ( $15 \mathrm{nl}$ ) of $20 \mathrm{mM}$ NMDA (A) and $10 \mathrm{mM}$ AMPA (B) into the AP. Left panels, control and effects immediately following the injection (filled bar). Right panels, recovery $30 \mathrm{~min}$ after the injection.

30-40 min. After NMDA microinjections, the respiratory frequency showed a mean increase of $88.3 \pm 17.5 \%$ (range $50-160 \%$ ) rising from baseline values of $42.5 \pm 1.6$ to $79.5 \pm 7.8$ breaths $\mathrm{min}^{-1}$ $(n=6 ; p<0.05)$. After AMPA microinjections the respiratory frequency increased by $92.1 \pm 9.7 \%$ (range $65.2-126.6 \%$ ) rising from $41.5 \pm 1.7$ to 80.1 \pm 4.5 breaths $\min ^{-1}(n=6 ; p<0.05)$. These excitatory effects on phrenic nerve activity were accompanied or, more often, preceded by an obvious gastric relaxation (Fig. 1). The onset of the gastric relaxation was rapid (5-20 s from the start of the injection); the maximum response in gastric motility occurred within 30-140s, while recovery followed a time course similar to that of respiratory effects. The magnitudes of gastric responses were $3.1 \pm 0.5 \mathrm{ml}$ (range 2-5 ml) after NMDA microinjections $(n=6$; $\mathrm{p}<0.05$ ) and $3.2 \pm 0.7 \mathrm{ml}$ (range 2-6.5 ml) after AMPA microinjections $(n=6 ; p<0.05)$. The effects on phrenic nerve activity and gastric motility were associated with small but significant increases ( $p$ always <0.05) in MAP of $9.2 \pm 3.8 \mathrm{mmH} g$ and $12.7 \pm 2.6 \mathrm{mmH} g$ for NMDA and AMPA, respectively.
Microinjections (10-20 nl) of both $10 \mathrm{mM}$ D-AP5 $(0.1-0.2 \mathrm{nmol})$ and $5 \mathrm{mM}$ NBQX $(0.05-0.1 \mathrm{nmol})$ caused respiratory depression and increases in gastric tone (Fig. 2). The respiratory frequency showed a mean decrease of $11.5 \pm 1.7 \%$ (from $45.3 \pm 1.8$ to $40.8 \pm 2.1$ breaths $\mathrm{min}^{-1}$ ) after D-AP5 microinjections $(n=9, p<0.005)$ and of $21.3 \pm 1.9 \%$ (from $43.1 \pm 1.8$ to $34.1 \pm 1.2$ breaths $\mathrm{min}^{-1}$ ) after $\mathrm{NBQX}$ microinjections $(n=9, p<0.005)$. These decreases were mainly due to an increase in the expiratory time. Peak phrenic amplitude did not vary significantly. These respiratory effects were accompanied by a mild increase in gastric tone Gastric volume showed a mean decrease of $1.9 \pm 0.4 \mathrm{ml}$ (range $0.5-3 \mathrm{ml}$ ) after D-AP5 microinjections $(n=9, p<0.005)$ and of $4.1 \pm 0.7 \mathrm{ml}$ (range 2-9 ml) after NBQX microinjections $(n=9, p<0.005)$. Both respiratory and gastric responses were more marked in response to N BQX microinjections $(p<0.05)$. Both effects showed a rapid onset (10-40 s from the start of the injection) and attained the maximum within 1-4 min; complete recovery occurred after $15-20 \mathrm{~min}$. No changes in MAP were observed. Microinjections of either $10 \mathrm{mM} \mathrm{D}$-AP5 $(n=4)$ or $5 \mathrm{mM} \mathrm{NBQX}(n=6)$ into the AP, performed at the same sites after bilateral vagotomy, failed to induce both gastric and respiratory responses. The effects of agonist and antagonist microinjections were reproducible both within and between animals; however, to obtain the same response at the same site it was necessary to wait at least $40 \mathrm{~min}$ for agonist microinjections and $60 \mathrm{~min}$ for antagonist microinjections. Control microinjections of equivalent volumes of the vehicle solution performed at the same locations did not induce any appreciable effect. Representative sites of microinjections of both EAA receptor agonists and antagonists are shown diagrammatically in Fig. 3.

\section{Discussion}

The effects obtained with microinjections of EAA receptor agonists indicate that both N MDA and nonN MDA ionotropic receptors are present on neurones located in the AP and that their activation has a role in the mediation of DLH-induced respiratory and gastric responses. 5,6 The presence of both N MDA and non-NMDA receptors on the same neurones is common in other areas of the central nervous system, such as, for instance, the nucleus tractus solitarii (NTS); ${ }^{7,12-14}$ it may reflect a mechanism modulating the strength of AP respiratory and gastric responses to appropriate excitatory inputs. In fact, at normal resting membrane potentials, activation of NMDA receptors is prevented by physiological concentrations of $\mathrm{Mg}^{2+}$. H owever, this block is voltage dependent and decreases as a neurone is depolarized. ${ }^{7,15}$ 


\section{A}

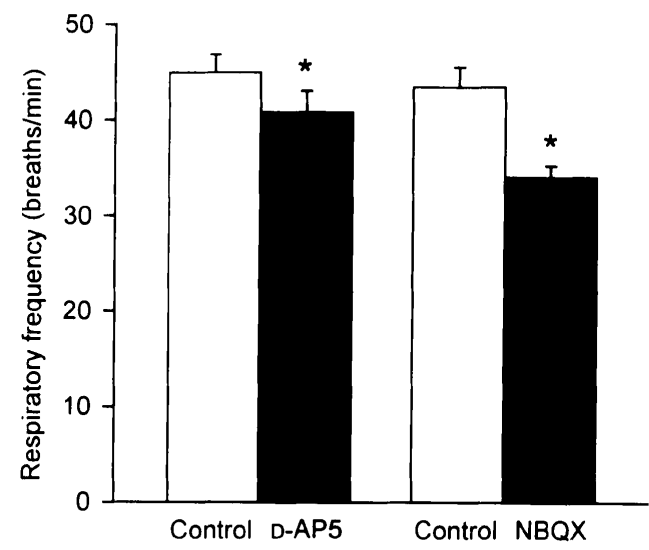

\section{C}

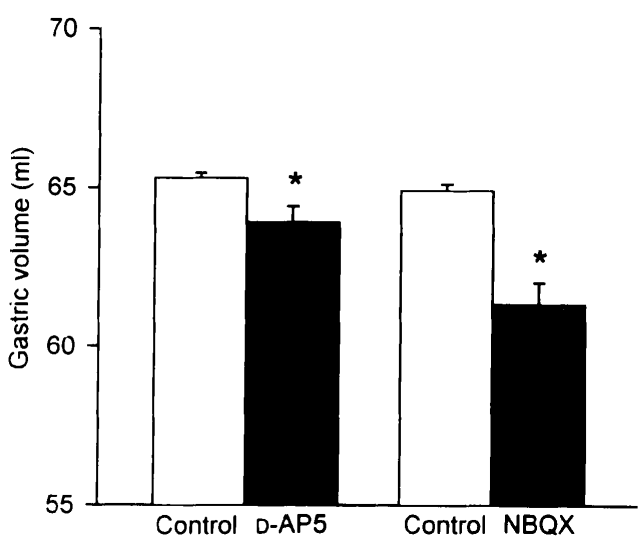

Control

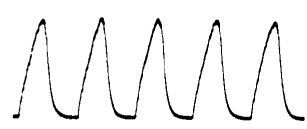

Control

IPA
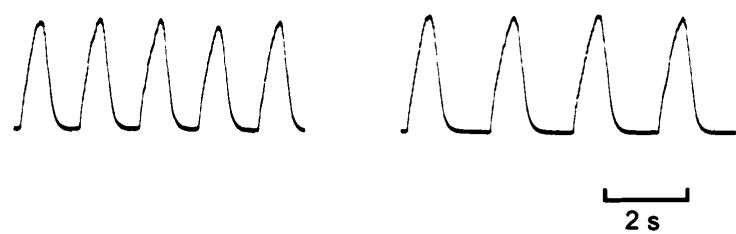

$\begin{array}{ll}\mathrm{GV}^{6} & \\ & \\ & \\ 65\end{array}[$
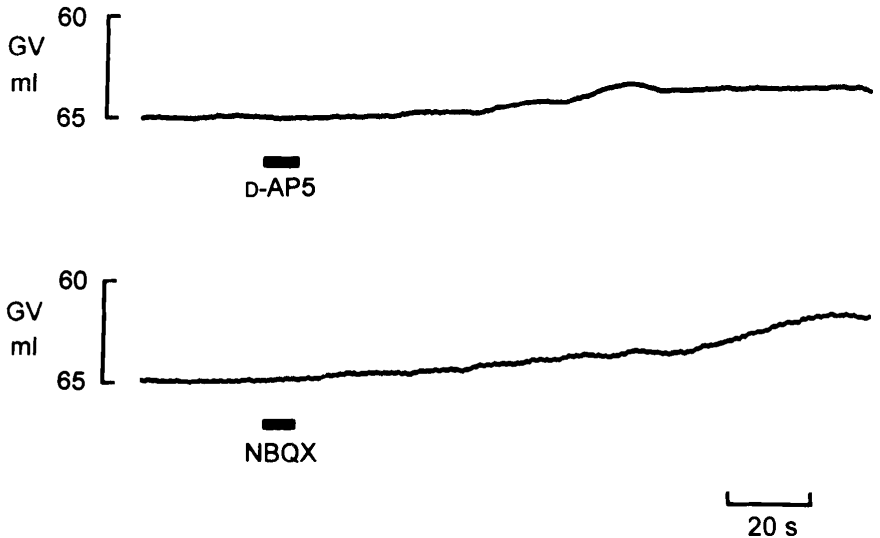

FIG. 2. Decreases in respiratory frequency and increases in gastric tone induced by $10 \mathrm{mM}$ D-AP5 or $5 \mathrm{mM}$ NBQX microinjected into the AP. Mean changes are illustrated by bar diagrams in $(\mathbf{A})$ and $(\mathbf{C})$, respectively. Reported values are means \pm s.e; $* p<0.005$. Examples of the effects on integrated phrenic nerve activity (IPA) 2 min after a microinjection ( $15 \mathrm{nl}$ ) of each type of EAA receptor antagonist are reported in (B). Examples of changes in gastric volume (GV) in response to a microinjection ( $15 \mathrm{nl}$ ) of D-AP5 or NBQX (filled bars) are reported in (D).

Thus, under conditions of sufficient depolarization, activation of NMDA receptors may modulate AP neuronal responses.

In agreement with our previous results, ${ }^{5}$ the activation of both NMDA and non-NMDA receptors caused small but consistent increases in blood pressure (Fig. 1), thus confirming that the AP may play a role in cardiovascular regulation. ${ }^{4}$ However, the absence of significant cardiovascular responses in vagotomized animals to DLH microinjections ${ }^{5,6}$ leads us to propose an interpretation similar to that suggested for DLH-induced effects, ${ }^{5}$ i.e. that the small pressor responses observed in this study are, to a great extent, secondary to mechanical changes due to increased respiratory activity. N evertheless, this does not completely rule out a role of vagus nerves in their modulation.

More interestingly, present results show that AP neurones exert tonic influences on both respiration and gastric motility via EAA receptors, with a larger involvement of non-N MDA receptors (Fig. 2). This result cannot be attributed to a failure to adequately block NMDA receptors in the AP, because both gastric and respiratory responses evoked by N MDA were virtually eliminated after D-AP5 administration (see Materials and Methods). The major role played by the non-N MDA receptors implies a more effective transmission of synaptic inputs through this type of 

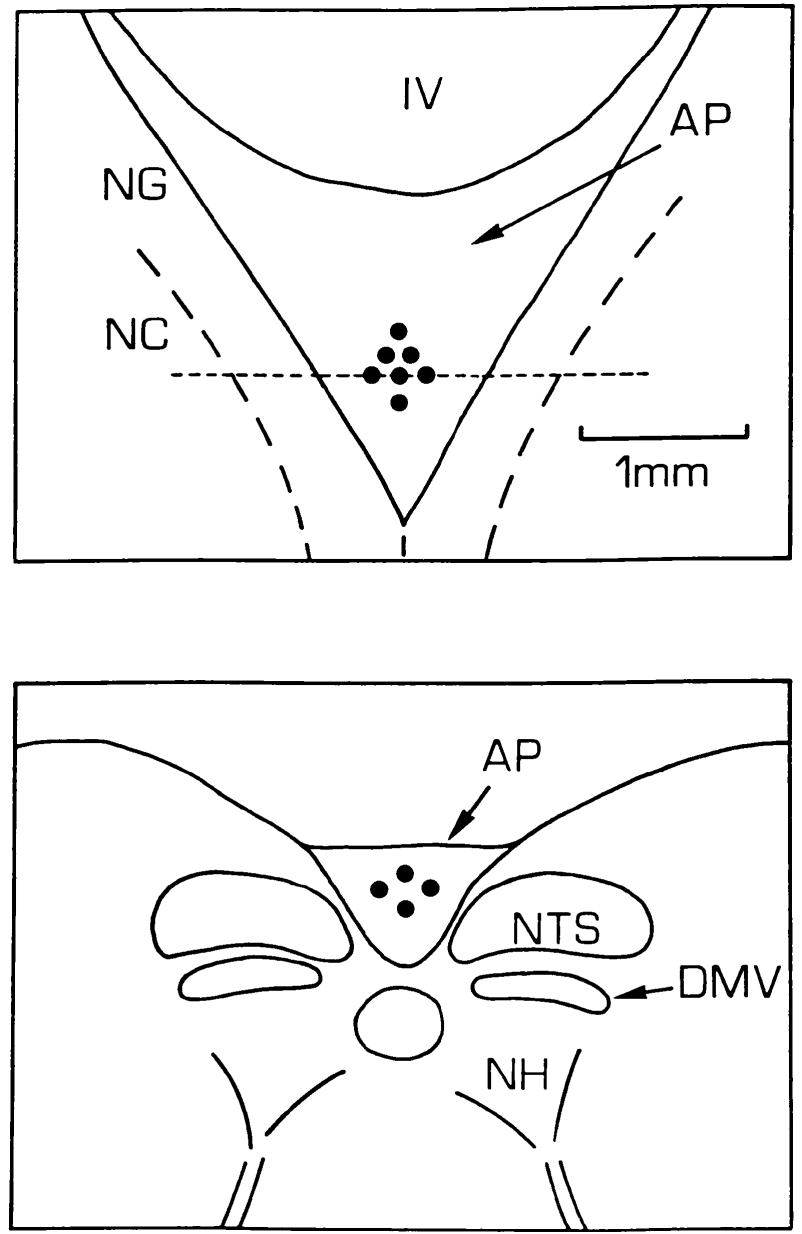

FIG. 3. Diagrammatic illustration of representative injection sites projected on a dorsal view of the AP (upper panel) and on a coronal section of the medulla oblongata at about $1.1 \mathrm{~mm}$ caudal to the rostral border of the AP (lower panel).The level of the selected coronal section is indicated by the horizontal dashed line in the upper panel. The outlines of the maps derive from the atlas of Shek et al. ${ }^{11} \mathrm{AP}$, area postrema; DMV, dorsal motor nucleus of the vagus nerve; NC, nucleus cuneatus; NG, nucleus gracilis; $\mathrm{NH}$, nucleus nervi hypoglossi; NTS, nucleus tractus solitarii; IV, fourth ventricle.

receptors. This is consistent with the presence of the al ready mentioned voltage sensitive $\mathrm{Mg}^{2+}$ blockade of N MDA receptor channels. ${ }^{7,15}$

The effects observed with both D-A P5 and N BQ X microinjections suggest that $A P$ cells receive an excitatory input probably via glutamate. Some of this excitation may arise from other areas of the central nervous system; ${ }^{1-3}$ however, the effects of bilateral vagotomy indicate that tonic influences of AP neurones are maintained by vagal afferent inputs. This is certainly true for respiratory activity, but it can only be hypothesized for gastric motility since vagotomy also affect efferent fibres to the stomach.

Central afferent projections of the vagus nerve have as the principal target sites the NTS and the adjacent AP; these projections include those of pulmonary, cardiac, gastrointestinal and baroreceptors afferents. ${ }^{1-3,16,17}$ At present, we can only speculate on the type of vagal receptors involved in these AP tonic influences; all three main types of pulmonary receptors (slowly adapting stretch receptors, rapidly adapting receptors and broncopulmonary C-fibre receptors) may contribute ${ }^{17}$ As to the control of gastric tone, a primary role could be played by mechanoreceptors in the muscle of the oesophagus and gastric body; however, mechanoreceptors and chemoreceptors in the gastric antrum and duodenum might also be involved. ${ }^{18}$

We have recently reported ${ }^{5,6}$ a complete discussion on the microinjection technique used in the present study. The complete recovery after drug application as well as the absence of effects in response to microinjections of equivalent or even larger volumes of the vehicle solution indicate that the observed responses are not due to toxicity or non-specific effects of pressure and volume

Evidence has been provided that glutamate is the most likely candidate as the neurotransmitter between some vagal primary afferent fibres and NTS neurones. These afferents include those arising from slowly adapting pulmonary stretch receptors, ${ }^{12}$ broncopulmonary $\mathrm{C}$-fibre endings ${ }^{19}$ and aortic baroreceptors. ${ }^{20,21}$ On the other hand, glutamate is considered the best candidate as the excitatory transmitter for other primary sensory afferents in the NTS ${ }^{13,22}$ as well as in other areas of the central nervous system. ${ }^{7,13}$ Thus, since both NTS and AP share the majority of vagal projections, ${ }^{1-3,16,17}$ it is conceivable that glutamate may also be involved in the neurotransmission between some primary vagal afferents and AP neurones. ${ }^{23}$

\section{Conclusions}

This study is the first to provide evidence that both NMDA and non-N MDA receptors are present in the AP of the rabbit and that their activation mediates excitatory respiratory responses and gastric relaxation. More interestingly, the results show that AP neurones are involved in the tonic control of respiration and gastric motility via both types of ionotropic EAA receptors, with a major contribution from non-N MDA receptors. Tonic AP influences on respiration, and conceivably also those on gastric tone, are mediated by the input conveyed by vagal afferents.

\section{References}

1. Carpenter DO. Central nervous system mechanisms in deglutition and emesis. In: Schultz SG, ed. Handbook of Physiology, Section 6, The Gastrointestinal System, Vol. I, Motility and Circulation. Bethesda: American Physiological Society, 1989: 685-714. 
2. Gillis RA, Quest J A, Pagani FD et al. Control centers in the central nervous system for regulating gastrointestinal motility. In: Schultz SG, ed. Handbook of Physiology, Section 6. The Gastrointestinal System, Vol. I, Motility and of Physiology, Section 6, The Gastrointestinal System, Vol. I, Motility and
Circulation. Bethesda: American Physiological Society, 1989: 621-684.

Circulation. Bethesda: American Physiological Society, 1989:

4. Borison HL. Prog Neurobiol 32, 351-390 (1989).

5. Bongianni $F$, Mutolo $D$, Srinivasan $M$ et al. Brain Res 646, 307-311 (1994).

6. Srinivasan M, Bongianni F, Fontana GA et al. J Physiol (Lond) 463, 409-420 (1993).

7. Monaghan DT, Bridges RJ and Cotman CW. Annu Rev Pharmcol Toxicol 29, 365-402 (1989).

8. Baccari MC, Calamai F and Staderini G. J Auton Nerv Syst 37, 125-136 (1992)

9. Abrahamsson $\mathrm{H}$, Jansson $\mathrm{G}$ and Martinson J. Acta Physiol Scand $\mathbf{8 8}$, 296-302 (1973)

10. Karius DR, Ling L and Speck DF. J Appl Physiol 76, 1293-1301 (1994).

11. Shek J W, Wen GY and Wisniewski HM. Atlas of the Rabbit Brain and Spinal Cord. Basel: Karger, 1986

12. Boham AC, Coles SK and McCrimmon DR. J Physiol (Lond) 464, 725-745 (1993)
13. Li C-S and Smith DV. J Neurophysiol 77, 1514-1525 (1997).

14. Mayer ML and Westbrook GL. Prog Neurobiol 28, 197-276 (1987).

15. Novak L, Bregestovski P, Ascher P et al. Nature 307, 462-464 (1984).

16. Kalia M. J Auton Nerv Syst 3, 451-481 (1981).

17. Kubin $L$ and Davies RO. Central pathways of pulmonary and airway vagal afferents. In: Dempsey J A and Pack Al, eds. Regulation of Breathing. New York: Marcel Dekker, Inc., 1995: 219-284.

18. Andrews PLR. Arch Int Pharmacodyn 303, 167-198 (1990).

19. Wilson CG, Zhang Z and Bonham AC. J Physiol Lond 496.3, 773-785 (1996).

20. Gordon FJ and Leone C. Brain Res 568, 319-322 (1991).

21. Talman WT, Perrone MH and Reiss DJ. Science 209, 813-815 (1980).

22. Vardhan A, Kachroo A and Sapru HN. Am J Physiol 264, R41-R50 (1993).

23. Sykes RM, Spyer KM and Izzo PN. Brain Res 762, 1-11 (1997).

ACKNOWLEDGEMENTS: This study was supported by grants from the Ministero della Università e della ricerca scientifica e tecnologica of Italy.

\section{Received 15 April 1998;}

accepted 18 April 1998 